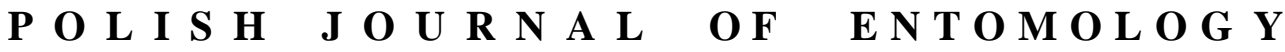

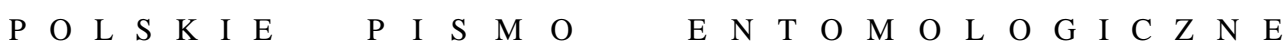

VOL. 87: 177-190

Lublin

30 June 2018

DOI: $10.2478 /$ pjen-2018-0013

\section{Host-age effects and the efficiency of the pupal parasitoid Dirhinus giffardii (SILVESTRI, 1913) (Hymenoptera: Chalcididae) against the melon fly Bactrocera cucurbitae (COQUILLETT, 1849) (Diptera: Tephritidae)}

\author{
SHAHID MEHMOOD ${ }^{1,2^{*}}$, KAMRAN SOHAIL ${ }^{2 *}$, MUHAMMAD QASIM ${ }^{3}$,

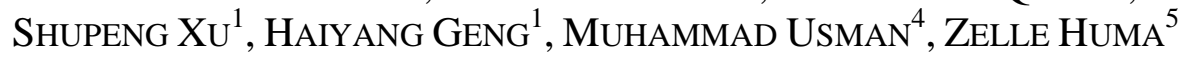 \\ ${ }^{1}$ Lab of Honeybee Molecular Breeding \& Health, College of Bee Science, Fujian \\ Agriculture and Forestry University, Fuzhou-350002, China \\ ${ }^{2}$ Department of Entomology, The University of Agriculture Peshawar-25000, Pakistan \\ ${ }^{3}$ Insect Ecology Lab, College of Plant Protection, Fujian Agriculture and Forestry \\ University, Fuzhou-350002, China \\ ${ }^{4}$ Department of Entomology, Bacha Khan University Charsadda-24420, Pakistan \\ ${ }^{5}$ Department of Plant Protection, The University of Agriculture Peshawar-25000, Pakistan
}

\begin{abstract}
Dirhinus giffardii is an efficient and aggressive pupal parasitoid of tephritid flies, including Bactrocera cucurbitae. Here we report on the various biological aspects of Dirhinus giffardii, mainly host-age preference, potential as well as the survival of this parasitoid from the pupae of different ages and its in vivo release against Bactrocera cucurbitae. The emergence rate of parasitoids was higher in old pupae than in fresh pupae. Similarly, the lifespan and potential of parasitoids emerged from older pupae were higher than those emerged from younger ones. The parasitoids reared on older pupae significantly controlled melon fly infestation in vivo. These findings suggest that parasitoids reared on older pupae of $B$. cucurbitae have a greater potential regarding fecundity, parasitism performance and survival, as these parasitoids effectively suppressed populations of B. cucurbitae under greenhouse conditions.
\end{abstract}

KEY WORDS: Cucurbit, Parasitoid wasp, Greenhouse conditions, Organic agriculture, Pesticide free, Bactrocera cucurbitae.

*Corresponding authors: shahidbee@aup.edu.pk, sohailagrian@ hotmail.com 


\section{INTRODUCTION}

The melon fly Bactrocera cucurbitae (CoQUILLETT, 1849) (Diptera: Tephritidae), one of the most destructive pests of vegetables, was first reported from India; it is also widely distributed in Pakistan, China, Nepal, New Guinea, the Philippines and the Hawaiian Islands, and all over most of southern Asia (WEEMS \& HEPPNER 2001). It damages over eighty-one (81) host plants and is reported to be a major pest of cucurbitaceous vegetables (DHILLON et al. 2005). In Pakistan, the melon fly causes 50-90\% losses of fruit. Guava, mango, citrus, melon and cucurbits are seriously affected (SAJJAD et al. 2017). The female fly lays her eggs in the soft, tender tissues by piercing them with the ovipositor; this results in a watery fluid oozing from the puncture and maggots developing inside the fruits (JACKSON et al. 2003). This species can also attack non-cucurbit hosts, damaging their flowers, stem and root tissues (OKE 2008).

The biological control of tephritid flies is gaining importance and succeeding in tropical and subtropical regions; successful applications have been reported from Hawaii, Florida, the USA, Fiji and Europe, and these are encouraging researchers to rear parasitoids and carry out field tests (PURCELL 1998). On Reunion Island, Fopius arisanus (SONAN, 1932) decreased the infestation and population rate of Bactrocera dorsalis (HENDEL, 1912), B. tryoni (FroGGATT, 1897) and B. kirki (FROGGATT, 1911) in guava fields: this is considered the classical biological method for the control of fruit flies outside Hawaii (VARGAS et al. 2007). The native Australian braconid parasitoids Diachasmimorpha tryoni (CAMERON, 1911) was applied against Bactrocera tryoni in the Australian region and was used to great effect in Hawaii and other locations (ZAMEK et al. 2012). Pachycrepoideus vindemmiae (RONDANI, 1875) can also be used as a biocontrol agent against Bactrocera dorsalis; it also has the capability to parasitize melon fly pupae at every stage (ZHAO et al. 2013a, 2013b). The hymenopteran Spalangia endius (WALKER, 1839) is the dominant pupal parasitoid of fruit flies and was successfully used against different-aged pupae of Bactrocera cucurbitae in vitro (TANG et al. 2015).

Dirhinus giffardii (SILVESTRI, 1913) (Hymenoptera: Chalcididae) is a general parasitoid that attacks a wide range of fruit-infesting tephritids, including Bactrocera cucurbitae, $B$. dorsalis, B. tryoni and B. oleae (ROSSI, 1790) (WHARTON \& YODER 2018). This parasitoid is native to West Africa, and its original host being Ceratitis capitate (WIEDEMANN, 1824). Besides tephritids, Dirhinus giffardii has the ability to parasitize dipterous houseflies (MOHAMED et al. 2006, WHARTON \& YODER 2018). It has also been used for the first time in West Africa to control Black Soldier fly (DEVIC \& MAQUART 2015).

Dirhinus giffardii penetrates the puparial wall of the fruit flies and oviposits inside the puparium, emerging from the pupa after completing its larval stage. It can produce larger offspring when females attack larger host species (WANG \& MESSING 2004a). The egg 
laying rate of $D$. giffardii starts to decline as it grows older, so for efficient mass rearing, it has been suggested that the parasitoids be discarded after 15 days (SHAH et al. 2014). Earlier, studies were undertaken to discover the efficacy of $D$. giffardii on differently aged pupa, but little research has been done on the potential, survival and the parasitism performance of this chalcid parasitoid wasp. Here we present these outcomes in vitro and in vivo; furthermore, the present study was planned to evaluate the performance of $D$. giffardii in controlling melon fly infestation in a summer squash field.

\section{MATERIALS AND METHODS}

\section{Rearing of melon flies and Dirhinus giffardii}

The experiment was carried out at the Nuclear Institute of Food \& Agriculture (NIFA), Peshawar, Pakistan. Individual melon flies were obtained from a culture maintained in the fruit fly laboratory $\left(27 \pm 1{ }^{\circ} \mathrm{C}, 60 \pm 5 \% \mathrm{RH}\right.$ with $14: 10 \mathrm{~h}$ photoperiod); fruits of summer squash (Cucurbita pepo L.) were used as a food source or host. Fresh cucurbits were provided on a regular basis and were placed in the melon fly cage $(1 \times 1 \times 1 \mathrm{~m})$. After two to three days, the infested fruits were transferred from the melon fly cage to a new wooden container covered with wheat bran $(3 \mathrm{~cm})$ for easy collection of pupae using plastic sieves. The newly emerged larvae lived inside the fruit and fed for 5-6 days until maturity; on completion of the larval stage, the larvae jumped into the wheat bran container for pupation. Pupae were sieved from this container and placed in the fruit fly cage for culturing. Sugar, yeast, honey and water were regularly supplied as a food supplement in Petri dishes. The cotton swabs in the Petri dishes were replaced regularly to prevent contamination.

Dirhinus giffardii adults were brought from Tando Jam, Punjab, Pakistan. Adults (3-5 $\mathrm{mm})$ were reared and maintained in large glass cages $(30 \times 30 \times 30 \mathrm{~cm})$; the ambient temperature was $15 \pm 1{ }^{\circ} \mathrm{C}$. Cotton swabs dipped in a syrup of honey and water were placed in the cage as food supplements. The previous rearing technique described by WANG \& Messing (2004b) was followed and modified for the in vitro tests: we used small Plexiglas cages $(15 \times 15 \times 15 \mathrm{~cm}$, easy to observe) with $70-80$ parasitoids per cage. Two- to four-day old melon fly pupae were supplied to the parasitoids in the Petri dish; after an exposure time of 8-24 h, the Petri dish was taken from the cage and placed in a new one for culturing. 


\section{Host-age preference, survival and parasitism potential of emerged parasitoids}

After completing the maggot stage inside the fruit, the melon fly larva jumped from the pupae for pupation, which took around 8-9 days (MIR et al. 2014). To investigate host-age preference, pupae of different ages $(12,24,48$ and $72 \mathrm{~h}$ ) were selected during the pupal period. These were transferred to $7 \mathrm{~cm}$ diameter Petri dishes containing a layer of wet tissue paper, and a $1 \mathrm{~cm}$ layer of wheat bran to prevent the pupae from drying out. Later, the different groups of melon fly pupae were provided to Dirhinus giffardii for $24 \mathrm{~h}$, after which the pupae were moved from the D. giffardii cage to new, small glass jars for recording the emergence rates of parasitoids. In addition, 20 newly emerged parasitoids from melon fly pupae of different ages were transferred to new, small glass jars for screening and observing their survival and mortality levels. In addition, 200 melon fly pupae (age not recorded) were supplied for two days to parasitoids emerged from fresh pupae and older pupae in order to record the parasitism efficacy of each group $(\geq 24 \mathrm{~h}$ and $\leq 48 \mathrm{~h}$ ) in vitro. The cages were shuffled, and the experiment was repeated three times. All the data were collected on a daily basis.

\section{In vivo performance of Dirhinus giffardii emerged from pupae of different ages}

To investigate the in vivo performance and infestation control rate between parasitoids emerged from pupae of different ages, a field experiment was carried out at the NIFA experimental block. The summer squash transplants were hand-planted in three different field plots, i.e. the $\geq 24 \mathrm{~h}$ parasitoids plot (parasitoids emerged from 12 and $24 \mathrm{~h}$ pupae), the $\leq 48 \mathrm{~h}$ parasitoids plot (parasitoids emerged from 48 and $72 \mathrm{~h}$ pupae) and the control plot (plot with no parasitoids or untreated). The basic experimental design and techniques according to NESMITH (1993) were followed but modified for the summer squash plantation. Each well-drained soil plot was 20 rows wide $(20 \mathrm{~m}$, row-row distance $1 \mathrm{~m})$ and $10 \mathrm{~m}$ long (10 transplants per row, plant-plant distance $1 \mathrm{~m}$ ). In addition, the field plots were cultivated with pre-control measures and were covered completely with thin white sieving cloth from the very first day to prevent the entry of other insect pests. Honey bees (Apis mellifera LinNaEus, 1761) in a small hive box $(10 \times 10 \times 10 \mathrm{~cm})$ were used as pollinators in each field plot. After several weeks, the field plots were inspected for fresh fruiting. At the same time 40 adult melon flies (19 to 21 aged individuals) were released in each field plot. After 7 days' exposure of the melon flies in the fields, 600 Dirhinus giffardii individuals ( 3 per plant manually) were released in each treated field plot (excluding the control field). The presence and activities of D. giffardii were observed on a daily basis. The experiment was carried out using a completely randomized block design with three replicates. 200 fruits (one from each plant) were selected randomly every week in order to acquire infestation data. 


\section{Data analysis}

All the experiments were performed at least three times. The emergence and survival rates of Dirhinus giffardii and infestation control rates of Bactrocera cucurbitae were recorded at different time points. All values are expressed as means \pm standard error. Analysis of Variance (ANOVA) and correlation analysis were used to evaluate the correlation between the number of parasitoid emergences and pupal age (12, 24, 48 and 72 h). ANOVA was also used to assess the significant differences between the fresh-pupae group (12 and $24 \mathrm{~h}$ ) and the old-pupae group (48 and $72 \mathrm{~h}$ ), and the significant differences of infestation among the three groups in each week. Pairwise comparisons for significant differences were evaluated using Tukey's post-hoc test. The Kaplan-Meier Survival Function was used to evaluate the survival of parasitoids emerged from pupae of different ages. Finally, pairwise comparisons for significant differences were evaluated using Log Rank (Mantel-Cox) and Breslow (Generalized Wilcoxon) tests.

\section{RESULTS}

\section{Dirhinus giffardii host-age preference}

Melon fly pupae of different ages were provided to D. giffardii, the emergence results were nearly the same in each treatment. The correlation was significant at the 0.01 level (two-tailed) with a Pearson correlation value of 0.971 (Table 1). Furthermore, the emergence of parasitoids in fresh $12 \mathrm{~h}$ pupae showed the lowest rate of emergence in all replicates; this was followed by the $24 \mathrm{~h}$ pupae group with mean values of $28.00 \pm 0.58$ and $29.33 \pm 0.33$, respectively. Although a significant difference was observed in older pupae $(\mathrm{p}<0.0001)$, the highest emergence rate of parasitoids was recorded with $72 \mathrm{~h}$ followed by $48 \mathrm{~h}$ old pupae (mean values of $39.00 \pm 0.58$ and $36.30 \pm 0.33$, respectively). These results indicated a high emergence rate in the $72 \mathrm{~h}$ pupae among the different age-groups in all replicates (Fig. 1). The parasitism performance of parasitoids emerged from the older pupae group (48 and $72 \mathrm{~h}$ ) was good enough in comparison with the fresh-pupae group (12 and 24 h). Moreover, the number of emergences recorded in the fresh group was significantly lower than in the old pupae group, with an $\mathrm{F}$ value of 73.778 and mean values of $113.67 \pm 3.712$ and $150.67 \pm 2.186$, respectively (Fig. 2). 
Table 1. Correlation between parasitoid emergence and age of pupae.

\begin{tabular}{|c|c|c|c|}
\hline & & Age & Number \\
\hline \multirow[t]{3}{*}{ Age } & Pearson correlation & 1 & $* * 0.971$ \\
\hline & Sig. (2-tailed) & & 0.000 \\
\hline & $\mathrm{N}$ & 12 & 12 \\
\hline \multirow[t]{3}{*}{ Number } & Pearson correlation & $* * 0.971$ & 1 \\
\hline & Sig. (2-tailed) & 0.000 & \\
\hline & $\mathrm{N}$ & 12 & 12 \\
\hline
\end{tabular}

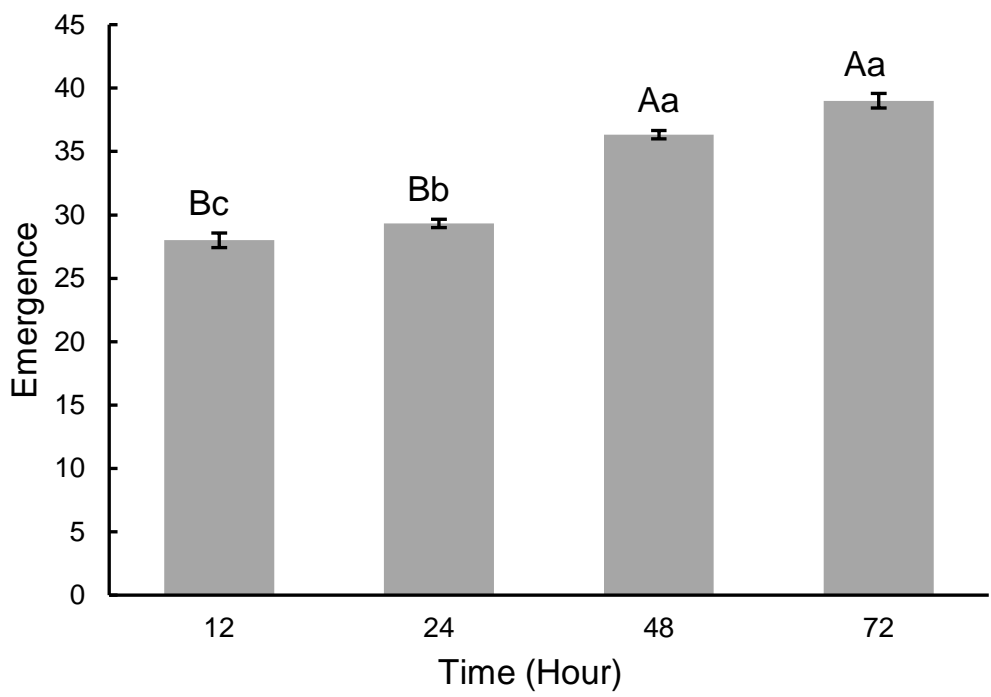

Fig. 1. The emergence rate of Dirhinus giffardii individuals from Bactrocera cucurbitae pupae of different ages. The columns marked 12, 24, 48 and 72 represent the age of the pupa (in hours) provided to Dirhinus giffardii for parasitism. The different capital letter represent significant difference at the 0.01 level, the different lowercase letter represent significant difference at the 0.05 level.

\section{Survival of emerged parasitoids from host pupae of different ages}

The survival of newly emerged parasitoids from parasitized pupae of different ages (12, 24, 48 and $72 \mathrm{~h}$ ) was observed during 1-20 days. The mean survival times were $10.567 \pm 0.805,10.783 \pm 0.796,14.550 \pm 0.800$ and $13.783 \pm 0.798$ days, respectively. Pairwise comparisons showed that the longevity of newly emerged parasitoids from the old-pupae group (48 and $72 \mathrm{~h}$ ) was significantly longer than fresh-pupae group (12 and $24 \mathrm{~h}$ ), with $P<0.01$ (Table 2, Fig. 3). 


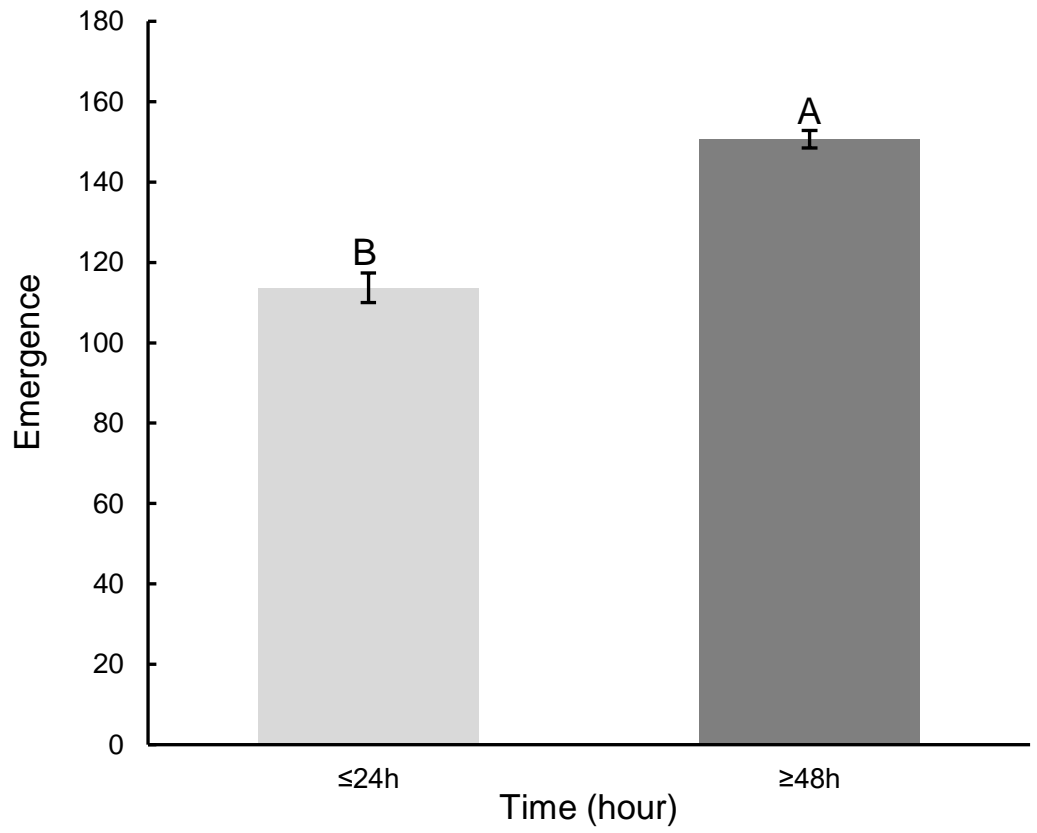

Fig. 2. The parasitism level of parasitoids, emerged from groups of different ages. $\leq 24 \mathrm{~h}$ represent the parasitoids emerged from 12 and $24 \mathrm{~h}$ old pupae, while $\geq 48$ represent the parasitoids emerged from 48 and $72 \mathrm{~h}$ old pupae. The different capital letter represent significant difference at the 0.01 .

Table 2. Pairwise comparisons for significant differences with Log Rank (Mantel-Cox) and Breslow (generalized Wilcoxon). The figures 12.00, 24.00, 48.00 and 72.00 represent the parasitized pupa; the parasitoids emerging from lower age-pupae live shorter than the other group (48 and $72 \mathrm{~h}$ ).

\begin{tabular}{|c|c|c|c|c|c|c|c|c|c|}
\hline \multicolumn{2}{|c|}{ Group } & \multirow{2}{*}{$\begin{array}{c}12.00 \\
\chi 2\end{array}$} & \multicolumn{3}{|c|}{24.00} & \multirow{2}{*}{$\begin{array}{c}48.00 \\
\chi^{2}\end{array}$} & \multicolumn{3}{|c|}{72.00} \\
\hline & & & Sig. & $x^{2}$ & Sig. & & Sig. & $x^{2}$ & Sig. \\
\hline \multirow{4}{*}{$\begin{array}{l}\text { Log Rank } \\
\text { (mantel-Cox) }\end{array}$} & 12.00 & & & 0.027 & 0.869 & 16.028 & 0.000 & 9.450 & 0.002 \\
\hline & 24.00 & 0.027 & 0.869 & & & 14.631 & 0.000 & 8.323 & 0.004 \\
\hline & 48.00 & 16.028 & 0.000 & 14.631 & 0.000 & & & 1.141 & 0.285 \\
\hline & 72.00 & 9.450 & 8.323 & 8.323 & 0.004 & 1.141 & 0.285 & & \\
\hline \multirow{4}{*}{$\begin{array}{l}\text { Breslow } \\
\text { (generalised } \\
\text { Wilcoxon) }\end{array}$} & 12.00 & & & 0.047 & 0.829 & 13.630 & 0.000 & 8.523 & 0.004 \\
\hline & 24.00 & 0.047 & 0.829 & & & 12.329 & 0.000 & 7.392 & 0.007 \\
\hline & 48.00 & 13.630 & 0.000 & 12.329 & 0.000 & & & 0.875 & 0.350 \\
\hline & 72.00 & 8.523 & 0.004 & 7.392 & 0.007 & 0.875 & 0.350 & & \\
\hline
\end{tabular}




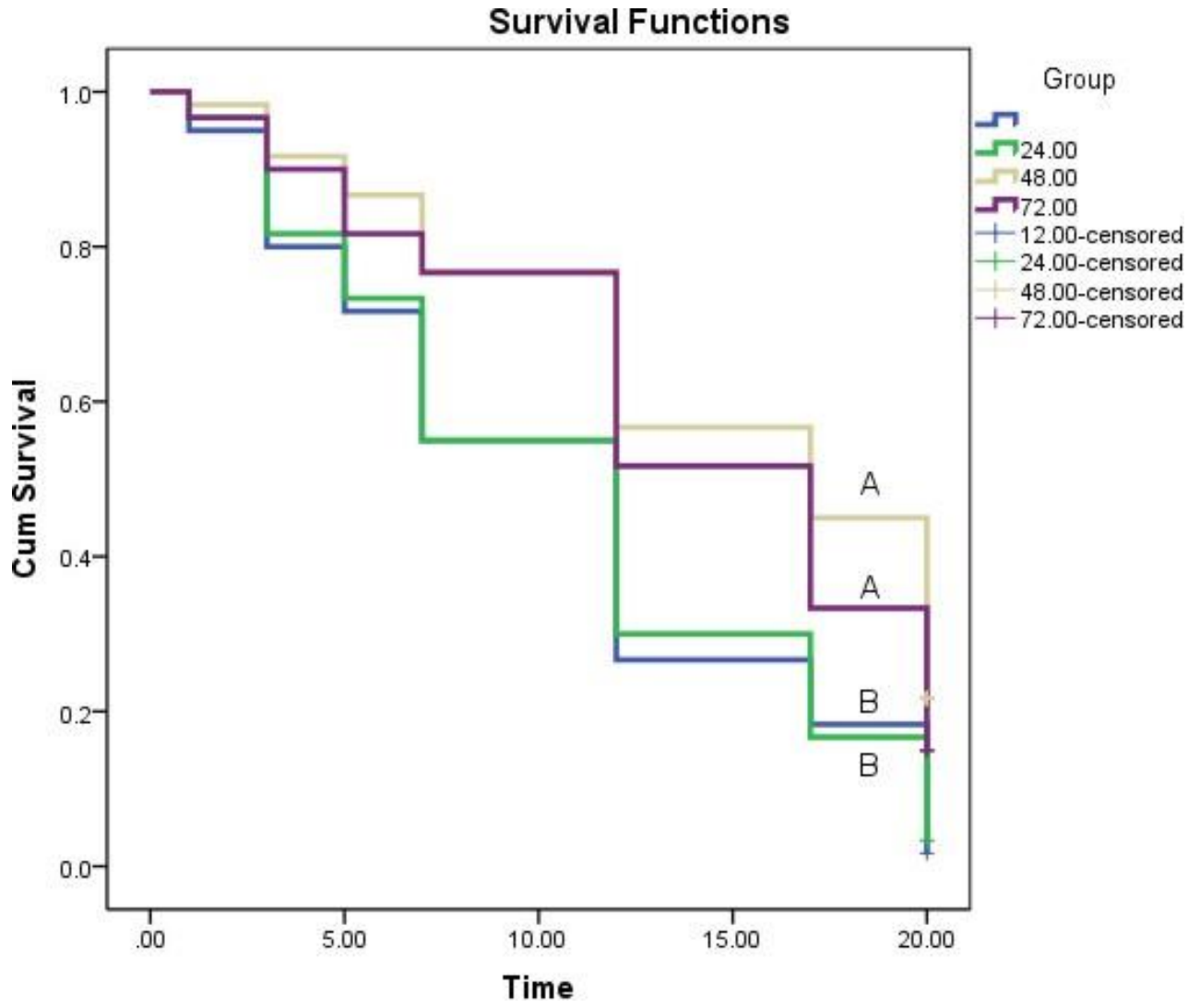

Fig. 3. Survival rate of parasitoids emerged from parasitized pupae of different ages (12, 24,48 and $72 \mathrm{~h}$ ). The figures $0.00-20.00$ on the x-axis represent survival time in days. The different capital letter represent significant difference at the 0.01 level, the different lowercase letter represent significant difference at the 0.05 level.

The effectiveness of parasitoids in controlling the infestation rate of Bactrocera cucurbitae in vivo

In the first three weeks after the parasitoids had been released, the results showed a roughly similar infestation in each field plot ( $\leq 24 \mathrm{~h}$ parasitoid plot, $\geq 48 \mathrm{~h}$ parasitoid plot and control), which started to increase after the third week. A significant variation in infestation was recorded among three groups after the third week. The parasitoids emerged from the $48 \mathrm{~h}$ and $72 \mathrm{~h}$ pupae exhibited a significant level of infestation control in comparison with parasitoids reared on $12 \mathrm{~h}$ and $24 \mathrm{~h}$ individuals. The highest level of infestation was recorded in the untreated or control field plot (Fig. 4). 


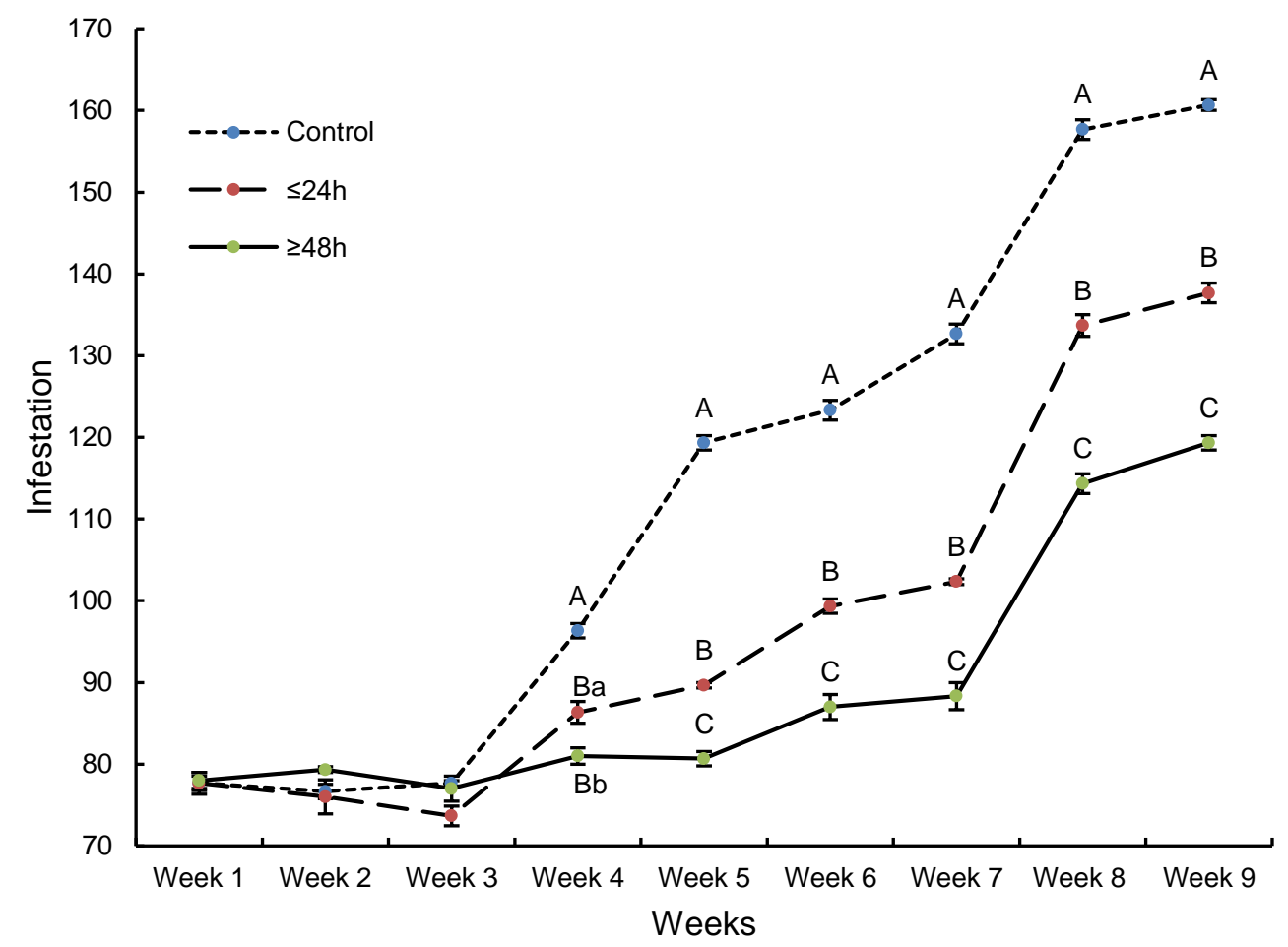

Fig. 4. In vivo efficacy of Dirhinus giffardii against the melon fly; $\leq 24 \mathrm{~h}$ represents the parasitoids emerged from 12 and $24 \mathrm{~h}$ old pupae, while $\geq 48$ represent the parasitoids emerged from 48 and $72 \mathrm{~h}$ old pupae used in the different field plots. "Control" means that the field plot was untreated or that no parasitoids were released. The different capital letter represent significant difference at the 0.01 level, the different lowercase letter represent significant difference at the 0.05 level.

\section{DISCUSSION}

As host age plays a very important role in the development of parasitoids, it is important for a parasitoid to select a host of suitable age for its development. Parasitoids can discriminate between host pupae of different ages, and then select a suitably aged host for parasitization; this offers an apparent advantage for the survival of the parasitoid population (DAHLMAN \& BRADLEIGH 1976). The present study confirmed that the pupal parasitoid Dirhinus giffardii, used to parasitize older-aged melon fly pupae, preferred older puparia to fresh ones throughout this study (WANG \& MESSING 2004b, NAVEED et al. 2014). Different hosts, different host instars or different host pupal ages may have different nutritional qualities (HARVEY 2000, HARVEY \& STRAND 2002). We provided pupae of different ages 
to D. giffardii individuals, and the results showed the highest level of parasitism in the oldest pupae. An identical maximum level of parasitism was recorded when D. giffardii individuals were used against Bactrocera zonata (SAUNDERS, 1842) at various depths of plant debris (ALI et al. 2016). Similarly, some other parasitoid wasps prefer older puparia for oviposition when they have a choice (HE \& WANG 2006, HE et al. 2011, TANG et al. 2015).

For a number of pupal parasitoids, the age at which the host pupa is parasitized influences offspring survival and parasitism performance. The present findings of the longevity and potential of parasitoids (Dirhinus giffardii) have been confirmed by those of EL-HUSSEINI et al. (2008), who stated that old parasitoid pupae are better than young ones. They lived longer and developed more quickly in comparison with parasitoids emerged from smaller pupae. Furthermore, a high mortality rate was recorded in younger parasitoids emerged from fresh pupae in the first week of emergence. The lower rate of parasitism on young pupae was associated with the relatively higher mortality of host pupae and emerging insects, suggesting that young pupae are more susceptible to injury caused during oviposition, including venom injections or stings or both. In contrast, parasitism did not seem to induce mortality in older pupae. Food quality is one of the most important factors, as pupae of different ages may not have the same nutritional quality. During pupal development, internal tissues undergo histolysis, histogenesis and differentiation to form adult internal organs and sclerotized appendages. Thus, older pupae may contain fewer resources for developing parasitoids (ECKENRODE \& CHAPMAN 1971). The oviposition decisions (i.e. host selection and sex allocation) of female parasitoids are expected to correspond with host quality, as the fitness of their offspring is dependent on the amount and quality of resources provided by a single host (STEPHENS \& KREBS 1986). Previously, different hymenopteran and braconid parasitoids were tested on host-pupae of different ages for their development, potential and progeny; this showed that older hosts or pupae or instars can increase the progeny level and development of parasitoids (IMANDEH 2006, WANG et al. 2008, TANG et al. 2015, SitThichaiYaKul \& AmORNSAK 2017). This suggested that there were some cues that allowed the parasitoids to discriminate between the hosts of different ages. Most parasitoids have the ability to determine host quality during oviposition (WANG \& LIU 2002, CHINWADA et al. 2003, LI et al. 2006, RORIZ et al. 2006); however, some prefer host pupae of medium age for their development (PfanNenstiel et al. 1996, Colinet et al. 2005). The ability of parasitoids to cope with hosts of variable quality would have the overall effect of determining host range.

Biological control using parasitoid wasps is an effective and safe approach for controlling tephritid flies. The method is successful and worth applying in the control of these pests (PURCELl 1998, VARGAS et al. 2007, ZAMEK et al. 2012, TANG et al. 2015). The parasitoid individuals in the summer squash field significantly controlled the fruits 
infestation level (Fig. 4). They parasitized Bactrocera cucurbiate pupae in the soil and were completely developed in the field conditions. We used Dirhinus giffardii for the first time in vivo against melon flies in cucurbit fields; however, this parasitoid has been successfully used and developed in field conditions against different fruit fly species in mango orchards (SHAH et al. 2014, SARWAR et al. 2015). Like other parasitoid species parasitizing tephritid flies (WONG et al. 1992, ARGOV \& GAZIT 2008).

The symptoms of melon fly disease in the cucurbit fruits are quite apparent: this must affect the market value of vegetables, with consequent capital losses to farmers. The experimental findings showed that this notorious pest can be effectively controlled, and it gave an easy direction to control Bactrocera MACQUART, 1835 species mainly melon fly. Furthermore, environmentally-friendly control of insect pests for the human wellbeing and environmental conservation is necessary.

\section{REFERENCES}

Ali S.S., Rattar I.A., Ahmed S.S., Bukero A., Rizwana H., NAZ S., RAtTar T.M. 2016. Searching ability of pupal parasitoid, Dirhinus giffardii (SILVESTRI) on Bactrocera zonata (Saunders) at various depths of plant debris. Journal of Basic and Applied Sciences 12: 164-169.

ARGOV Y., GAZIT Y. 2008. Biological control of the Mediterranean fruit fly in Israel: Introduction and establishment of natural enemies. Biological Control 46(3): 502-507.

Chinwada P., Overholt W.A., Omwega C.O., Mueke J.M. 2003. Geographic differences in host acceptance and suitability of two Cotesia sesamiae populations in Zimbabwe. Biological Control 28(3): 354-359.

Colinet H., Salin C., Boivin G., Hance T.H. 2005. Host age and fitness-related traits in a koinobiont aphid parasitoid. Ecological Entomology 30(4): 473-479.

Dahlman D.L., BRadLeigh V.S. 1976. Trehalose level in the hemolymph of Heliothis virescens parasitized by Campoletis sonorensis. Annals of the Entomological Society of America 69(3): $523-524$.

Devic E., Maquart P.-O. 2015. Dirhinus giffardii (Hymenoptera: Chalcididae), parasitoid affecting Black Soldier Fly production systems in West Africa. Entomologia 3(284): 25-27.

Dhillon M.K., Singh R., NAResh J.S., Sharma H.C. 2005. The melon fruit fly, Bactrocera cucurbitae: A review of its biology and management. Journal of Insect Science 5(1): 1-16.

ECKENRODE C.J., CHAPMAN R.K. 1971. Effect of various temperatures upon rate of development of the cabbage maggot under artificial conditions. Annals of the Entomological Society of America 64(5): 1079-1083.

El-Husseini M.M., Agamy E.A., SAafan M.H., AbD E.-K. 2008. On the biology of Dirhinus giffardii (SiLVESTRI) (Hymenoptera: Chalcididae) parasitizing pupae of the peach fruit fly, Bactrocera zonata (SAUnDERS) (Diptera: Tephritidae) in Egypt. Egyptian Journal of Biological Pest Control 18(2): 391-396. 
HARVEY J.A. 2000. Dynamic effects of parasitism by an endoparasitoid wasp on the development of two host species: implications for host quality and parasitoid fitness. Ecological Entomology 25(3): 267-278.

HARVEY J.A., STRAND M.R. 2002. The developmental strategies of endoparasitoid wasps vary with host feeding ecology. Ecology 83(9): 2439-2451.

He X.Z., WANG Q. 2006. Host age preference in Aphidius ervi (Hymenoptera: Aphidiidae). New Zealand Plant Protection 59: 190-194.

He X.Z., Wang Q., Teulon D.A. 2011. Host age preference behavior in Aphidius ervi Haliday (Hymenoptera: Aphidiidae). Journal of Insect Behavior 24(6): 447.

IMANDEH N.G. 2006. Effect of the pupal age of Calliphora erythrocephala (Diptera: Calliphoridae) on the reproductive biology of Melittobia acasta (WALKER) (Hymenoptera: Chalcidoidea: Eulophidae). Entomological Science 9(1): 7-11.

JaCKSON C.G., VARgas R.I., SudA D.Y. 2003. Populations of Bactrocera cucurbitae (Diptera: Tephritidae) and its parasitoid, Psyttalia fletcheri (Hymenoptera: Braconidae) in Coccinia grandis (Cucurbitaceae) or ivy gourd on the island of Hawaii. Proceedings of the Hawaiian Entomological Society 36: 39-46.

Li J., Coudron T.A., PAN W., LIU X., Lu Z., ZhANG Q. 2006. Host age preference of Microplitis mediator (Hymenoptera: Braconidae), an endoparasitoid of Mythimna separata (Lepidoptera: Noctuidae). Biological Control 39(3): 257-261.

Mir S.H., DAR S.A., Mir G.M., Ahmad S.B. 2014. Biology of Bactrocera cucurbitae (Diptera: Tephritidae) on cucumber. Florida Entomologist 97(2): 753-758.

Mohamed S.A., Wharton R.A., von MÉRey G., Schulthess F. (2006) Acceptance and suitability of different host stages of Ceratitis capitata (WIEDEMANN) (Diptera: Tephritidae) and seven other tephritid fruit fly species to Tetrastichus giffardii SILVESTRI (Hymenoptera: Eulophidae). Biological Control 39(3): 262-271.

Naveed M., Suhail A., Ahmad N., Rauf I., Akbar W. 2014. Role of Dirhinus giffardii Silv. age on the parasitism preference to different days old pupae of Bactrocera zonata and Bactrocera cucurbitae. Journal of Agricultural Biotechnology and Sustainable Development 6(1): 1-5.

NESMith D. 1993. Transplant age influences summer squash growth and yield. HortScience 28(6): $618-620$.

OKE O.A. 2008. Effectiveness of two insecticides to control melon fruit fly (Bactrocera cucurbitae CoQ.) in cucumber (Cucumis sativus L). crop at Anse Boileau Seychelles. European Journal of Scientific Research 22(1): 84-86.

Pfannenstiel R.S., Browning H.W., SMith JR J.W. 1996. Suitability of Mexican rice borer (Lepidoptera: Pyralidae) as a host for Pediobius furvus (Hymenoptera: Eulophidae). Environmental Entomology 25(3):672-676.

PURCELL M.F. 1998. Contribution of biological control to integrated pest management of tephritid fruit flies in the tropics and subtropics. Integrated Pest Management Reviews 3(2): 63-83.

Roriz V., Oliveira L., GarCIA P. 2006. Host suitability and preference studies of Trichogramma cordubensis (Hymenoptera: Trichogrammatidae). Biological Control 36(3): 331-336.

Sajuad M., Hafiz M., Muhammad N., Muhammad T. 2017. Fruit Fly - A Serious Insect Pest of Horticultural Crops in Pakistan. Internet: https://www.technologytimes.pk/?p=17197 
Sarwar M., Ahmad N., Rashid A., Shah S.M.M. 2015. Valuation of gamma irradiation for proficient production of parasitoids (Hymenoptera: Chalcididae \& Eucoilidae) in the management of the peach fruit-fly, Bactrocera zonata (SAUNDERS). International Journal of Pest Management 61(2): 126-134.

Shah S.M.M., Ahmad N., SARwar M., Tofique M. 2014. Rearing of Bactrocera zonata (Diptera: Tephritidae) for parasitoids production and managing techniques for fruit flies in mango orchards. International Journal of Tropical Insect Science 34(S1): S108-S113.

SitThichaiYAKUl S., AMORNSAK W. 2017. Host-substrate preference of Theocolax elegans (WeSTwOOd) (Hymenoptera: Pteromalidae), a larval parasitoid of the maize weevil, Sitophilus zeamais (MOTSCHULSKY) (Coleoptera: Curculionidae). Agriculture and Natural Resources 51(1): $36-39$.

TANG L.-D., Ji X.-C., HAN Y., Fu B.-L., LiU K. 2015. Parasitism, emergence, and development of Spalangia endius (Hymenoptera: Pteromalidae) in pupae of different ages of Bactrocera cucurbitae (Diptera: Tephritidae). Journal of Insect Science 15(1): 15.

VARgas R.I., Leblanc L., PUTOA R., Eitam A. 2007. Impact of introduction of Bactrocera dorsalis (Diptera: Tephritidae) and classical biological control releases of Fopius arisanus (Hymenoptera: Braconidae) on economically important fruit flies in French Polynesia. Journal of Economic Entomology 100(3): 670-679.

WANG X.G., LiU S.S. (2002) Effects of host age on the performance of Diadromus collaris, a pupal parasitoid of Plutella xylostella. BioControl 47(3): 293-307.

Wang X.G., Messing R.H. (2004a) Two different life-history strategies determine the competitive outcome between Dirhinus giffardii (Chalcididae) and Pachycrepoideus vindemmiae (Pteromalidae), ectoparasitoids of cyclorrhaphous Diptera. Bulletin of Entomological Research 94(5): 473-480.

Wang X.G., Messing R.H. 2004b. Potential interactions between pupal and egg-or larval-pupal parasitoids of tephritid fruit flies. Environmental Entomology 33(5): 1313-1320.

WANG X.-.Y, YANG Z.-Q., Wu H., Gould J.R. 2008. Effects of host size on the sex ratio, clutch size, and size of adult Spathius agrili, an ectoparasitoid of emerald ash borer. Biological Control 44(1): $7-12$.

WeEms H.V., HePPNeR J.B. 2001. Melon fly, Bactrocera cucurbitae CoQuilletT (Insecta: Diptera: Tephritidae). Florida Department of Agriculture and Consumer Services, Division of Plant Industry, and T.R. Fasulo, University of Florida. University of Florida Publication EENY - 199.

Wharton R.A., Yoder M.J. 2018. Parasitoids of Fruit-Infesting Tephritidae. Internet: http://paroffit.org (accessed on Tue Feb 06 03:27:16 -0600 2018)

Wong T.T.Y., RAMADAN M.M., HERR J.C., MCInNis D.O. 1992. Suppression of a Mediterranean fruit fly (Diptera: Tephritidae) population with concurrent parasitoid and sterile fly releases in Kula, Maui, Hawaii. Journal of Economic Entomology 85(5): 1671-1681.

Zamek A.L., Spinner J.E., Micallef J.L., GurR G.M., Reynolds O.L. 2012. Parasitoids of Queensland fruit fly Bactrocera tryoni in Australia and prospects for improved biological control. Insects 3(4): 1056-1083.

Zhao H.-.Y, Liu K., Ali S., Lu Y.-Y., Zeng L., Liang G.-W. 2013a. Host suitability of different pupal ages of oriental fruit fly, Bactrocera dorsalis, for the parasitoid, Pachycrepoideus vindemmiae. Pakistan Journal of Zoology 45(3): 673-678. 
Zhao H.-.Y, Zeng L., Xu Y.-J., LU Y.-Y., LiANG G.-W. 2013b. Effects of host age on the parasitism of Pachycrepoideus vindemmiae (Hymenoptera: Pteromalidae), an ectoparasitic pupal parasitoid of Bactrocera cucurbitae (Diptera: Tephritidae). Florida Entomologist 96(2): 451-457.

Received: 24 November 2017

Accepted: 6 February 2018 